\title{
Vietnamese-speaking psychiatrists
}

We have recently had a request from a Member of the College for the name of a psychiatrist who is able to speak Vietnamese. The College does maintain a list of psychiatrists who speak or understand differ- ent languages and are willing to assist patients. It would be very helpful to include the name(s) of any psychiatrists able to speak Vietnamese. Please write to Vanessa Cameron, Secretary.

\section{Spring Bank Holiday}

The College will be closed from 7.00 pm on Thursday, 24 May and will re-open at 8.00 am on Tuesday, 29 May 1990.

Psychiatric Bulletin (1990), 14, 315

\section{Obituary}

\section{Editor: Henry R. Rollin}

Brian Edward Oliver, Consultant Psychiatrist, North Warwickshire Health Authority

Brian Oliver was born on 3 November 1936 and died on 9 November 1989. He graduated MB, ChB from Sheffield University and having decided on a career in psychiatry obtained the DPM from Sheffield in 1959. He was elected to the Foundation Membership of the College in 1971 and proceeded to the Fellowship in 1986.

Dr Oliver was appointed a full-time Consultant Psychiatrist at Chelmsley Hospital, North Warwickshire Health Authority in 1966. For several years he had been the medical representative on the North Warwickshire Mental Handicap Unit. He was also chairman of the Solihull District planning team and member of the North Birmingham District Handicap team. For the past five years he was the chairman of the Regional Mental Handicap Services Committee. In the community he provided support services to adult training centres, special schools and residential units in Solihull District catchment area. He took an active part in the teaching of under and postgraduate medical students in his capacity as Post-Graduate Clinical Tutor to Birmingham University. In addition he lectured to nursing and social work students at the Lanchester Polytechnic in Coventry and Birmingham Polytechnic.

Nationally, he was involved with the British Institute of Mental Handicap and the British Society for the Study of Mental Subnormality. He had also been a member of the Psychiatry of Mental Handicap executive committee, the Special Advisory committee for Mental Handicap and Clinical Tutors Sub-committee of the Royal College of Psychiatrists.

Throughout his working life he promoted an interdisciplinary approach to the care and management of people with mental handicap and their families. He was, as part of this approach, a member of the paediatric assessment team at the East Birmingham Hospital.

Brian Oliver was a truly dedicated professional who worked unstintingly to establish and improve facilities for mentally handicapped children, adults and their families. He understood their needs and adjusted his services and views to meet them in the most appropriate manner possible.

In the months preceding his death he was the victim of a severe illness which caused him considerable hardship as he had never been seriously ill in his life before this. Nevertheless, he bore it with fortitude, rarely complaining, and tried up to the end of his life to continue with his professional duties. Throughout his life Brian was a kind, gentle, caring person who was dearly loved by his staff, colleagues and the people he treated and supported without exception. Dedication and devotion of the degree shown by him are rare and as always such singular people are sorely missed.

He is survived by his wife Maureen and their two sons Mark and David.

GBS

AR 